\title{
The acute effects of different sources of dietary calcium on postprandial energy metabolism
}

\author{
Nicola K. Cummings, Anthony P. James and Mario J. Soares* \\ Program of Nutrition, Dietetics and Food Science, School of Public Health, Curtin University of Technology, GPO Box U1987, \\ Perth, WA 6845, Australia
}

(Received 18 October 2005 - Revised 2 March 2006 - Accepted 13 March 2006)

\begin{abstract}
Dairy $\mathrm{Ca}$ intake has been shown to be superior to elemental $\mathrm{Ca}$ in increasing the loss of body fat during energy restriction. We questioned whether the mechanisms involved an increase in postprandial energy expenditure, fat oxidation and/or a greater lipolysis. The acute effects of different sources of Ca were examined in eight subjects, aged $47-66$ years and BMI $27 \cdot 6-36 \cdot 1 \mathrm{~kg} / \mathrm{m}^{2}$, in a three-way cross-over study. Subjects were randomly provided breakfast meals either low in dairy Ca and vitamin $\mathrm{D}$ (LD; control), high in non-dairy Ca (calcium citrate) but low in vitamin D (HC) or high in dairy $\mathrm{Ca}$ and vitamin D (HD). Diet-induced thermogenesis, fat oxidation rates (FOR), carbohydrate oxidation rates (COR), insulin, glucose, NEFA and glycerol were measured hourly over a $6 \mathrm{~h}$ postprandial period. Postprandial data were calculated as a change $(\Delta)$ from the fasting value. Results showed that $\triangle$ NEFA was significantly different between meals (LD - 1.50 (SEM 0.26), HC - 1.22 (SEM 0.32), HD $-0.94($ SEM 0.27$) \mathrm{mmol} / \mathrm{l} \times 6 \mathrm{~h} ; P=0.035)$, with a lesser suppression following both high-Ca meals. $\Delta$ FOR was significantly higher following the two high-Ca meals (LD -6.5 (SEM 2.2), HC 2.93 (SEM 2.34), HD 3.3 (SEM 2.5) g $\times 6$ h; $P=0.005$ ), while reciprocally $\Delta$ COR was significantly lower. $\Delta$ Glycerol was less suppressed following the high-Ca meals but statistical significance was not achieved. No differences in diet-induced thermogenesis, insulin or glucose were observed. Regardless of source, Ca intake acutely stimulated postprandial fat oxidation; and there was a lesser suppression of NEFA following these meals.
\end{abstract}

\section{Calcium: Vitamin D: Thermogenesis: Fat oxidation: Obesity}

The epidemic of obesity, and its co-morbidities of dyslipidaemia, insulin resistance and CVD, is now a global problem. The prevalence of overweight and obesity in Australia increases with age and is greatest in the 55-64-year age group (Thorburn, 2005). Overall, it is more common for Australians to have a weight problem, with $48 \%$ men and $30 \%$ women being overweight and a further $19 \%$ men and $22 \%$ women, obese (National Health and Medical Research Council, 1997). Interestingly, $50 \%$ of the adult Australian population are consuming $\mathrm{Ca}$ at well below the recommended dietary intake (Australian Bureau of Statistics, 1998). Vitamin D, a key regulator in $\mathrm{Ca}$ status, is also of concern. Recent Australian data state that $70 \%$ of the elderly and institutionalised Australian population have a frank or sub-optimal vitamin D status, while $23 \%$ younger Australians seem to have a poor vitamin D status (Nowson \& Margerison, 2002). The co-existence of poor $\mathrm{Ca}$ status and overweight or obesity presents a tantalising paradigm for public health intervention.

The regulation of $\mathrm{Ca}$ homeostasis is important to a large number of physiological processes, from blood clotting to muscle contraction to enzyme secretion. Over the years the role of $\mathrm{Ca}$ in osteoporosis and hypertension has been well established. However, until recently the role of $\mathrm{Ca}$ in obesity and type 2 diabetes was unheard of. Zemel et al. (2000) propose that intracellular $\mathrm{Ca}$ holds the key to regulation of insulin sensitivity, lipid storage and synthesis. Interestingly Zemel's tenet arose from clinical trials on hypertension, where it was observed that increasing the intake of $\mathrm{Ca}$ from about 400 to $1000 \mathrm{mg} / \mathrm{d}$ resulted in significant weight loss. Zemel speculated that the increased calcitrophic hormones (vitamin $\mathrm{D}_{3}$ ) secondary to a low $\mathrm{Ca}$ intake stimulated adipocyte $\mathrm{Ca}$ influx, which in turn stimulated fatty acid synthase activity and hence lipid storage (Zemel et al. 2000). If this is true, increasing $\mathrm{Ca}$ intake should lower calcitrophic hormones, reduce intracellular $\mathrm{Ca}$ and protect against fat gain.

A number of epidemiological studies have supported Zemel's original findings with a strong inverse correlation between $\mathrm{Ca}$ intake and adiposity (Parikh \& Yanovski, 2003) and that individuals with the lowest $\mathrm{Ca}$ intake tend to have the highest body weight. Data from the National Health and Nutrition Examination Survey III also showed a strong inverse association for relative risk of obesity and $\mathrm{Ca}$ intakes (Zemel et al. 2000). Similar relationships have also been demonstrated in the Australian population, based on an examination of the data from the National Nutrition Survey 1995 (Soares et al. 2004a). The results indicated that Australian men and women with higher $\mathrm{Ca}$ intakes had lower BMI as well as waist circumferences, on controlling for various confounders

Abbreviations: COR, carbohydrate oxidation rate; FOR, fat oxidation rate; HC, high non-dairy Ca (calcium citrate) and low vitamin D; HD, high dairy Ca and vitamin D; LD, low dairy Ca and vitamin D (control).

* Corresponding author: Dr Mario J. Soares, fax +61 89266 2958, email m.soares@curtin.edu.au 
(Soares et al. 2004a). Retrospective analyses lend support to the thesis that $\mathrm{Ca}$ may influence the regulation of body weight. Davies et al. (2000) re-evaluated the results from five clinical studies (one intervention and four observational studies) looking at dietary $\mathrm{Ca}$ and bone mineral content. The results of Davies et al. (2000) showed a significant negative association between $\mathrm{Ca}$ intake and weight for all age groups; however, it is important to point out that with these early studies, weight or fat loss was not the major end point. More recently three clinical studies have documented that a high-dairy-Ca diet accelerated fat loss, particularly from the abdominal region. These results were obtained under energydeficit conditions (Zemel, 2004, 2005a,b), as well as during weight maintenance (Zemel et al. 2005b). The studies of Thompson et al. (2005) and Harvey-Berino et al. (2005), however, did not replicate these outcomes. Both studies concluded that a high-Ca diet did not augment weight loss above that obtained from energy restriction alone. Clearly, the issue is far from settled.

The present study examined the acute effects of increasing $\mathrm{Ca}$ intake on postprandial thermogenesis and substrate oxidation in overweight and obese subjects. It was based on the hypothesis that an increase in $\mathrm{Ca}$ intake would stimulate fat oxidation and thermogenesis, and that $\mathrm{Ca}$ from dairy sources would be superior to elemental (non-dairy) $\mathrm{Ca}$ in these effects.

\section{Methods}

\section{Study design}

The study was a single-blind, within-subject randomised comparison of the acute responses to three isoenergetic mixed meals. The interval between trials ranged from 2 to 3 weeks, and subjects were instructed to maintain their habitual intake and activity patterns throughout the study.

\section{Subjects}

Eight subjects, six men and two postmenopausal women, aged between 47 and 66 years and BMI within the range $27 \cdot 6-36 \cdot 1 \mathrm{~kg} / \mathrm{m}^{2}$, who were residents of Perth, WA, were recruited by advertisement in the local media (for subject details, see Table 1). Subjects were screened by a telephone questionnaire and selected individuals underwent an appointment with

Table 1. Physical and metabolic characteristics of the ten subjects*

(Mean values with their standard errors)

\begin{tabular}{lrl}
\hline & Mean & SEM \\
\hline Age (years) & 53.7 & 2.28 \\
Weight $(\mathrm{kg})$ & 92.4 & 6.97 \\
BMl $\left(\mathrm{kg} / \mathrm{m}^{2}\right)$ & 32.5 & 0.97 \\
Fat mass $(\mathrm{kg})$ & 31.6 & 2.82 \\
Fat-free mass $(\mathrm{kg})$ & 63.3 & 7.23 \\
Waist circumference $(\mathrm{cm})$ & 108.1 & 3.76 \\
Serum vitamin $\mathrm{D}_{3}(\mathrm{nmol} / \mathrm{l})$ & 75.5 & 7.62 \\
Fasting triacylglycerol $(\mathrm{mM})$ & 1.7 & 0.025 \\
Fasting LDL (mM) & 3.4 & 0.06 \\
Fasting HDL (mM) & 0.7 & 0.0058 \\
\hline
\end{tabular}

* Six males and two females. the chief investigator to explain the test-day protocol and familiarise the subjects with indirect calorimetry measurements. Inclusion criteria included: (i) absence of clinical signs or symptoms of chronic disease; (ii) history of weight stability ( $\pm 2 \mathrm{~kg}$ for the preceding 12 months); (iii) not on medication affecting metabolic rate or body composition; (iv) resting diastolic blood pressure $<90 \mathrm{mmHg}$; (v) for the women, at least 2 years postmenopausal; (iv) for the women, not on hormone replacement therapy. All subjects gave written informed consent to participate in the study. The Human Research Ethics Committee of Curtin University of Technology (HR 245-2001) approved the protocol. All measurements were made in the clinical rooms of the Bentley Campus of Curtin University (Perth, WA, Australia).

\section{Test meals}

The composition of the test breakfasts is provided in Table 2. The meals contained the following foods to meet the percentage macronutrients and $\mathrm{Ca}$ goals (Table 2): white bread (Goodman Fielder, Malaga, WA, Australia); butter (Bowland Dairies Pty Ltd, Rowville, Vic, Australia); Adelphi ham and tomato (Coles Supermarket, Karawara, West Australia); muesli bar (Uncle Toby's, Wahgunyah, Vic, Australia). One meal was supplemented by a low-Ca, low-vitamin D UHT milk (LD; control). One meal was supplemented with a high-Ca, high-vitamin D milk (HD). All milks were provided by Murray Gouldburn Co-Operative Co. Ltd (Brunswick, Vic, Australia). One meal was supplemented with orange juice (Berri Ltd, Carlton, Vic, Australia), and consumed with two tablets of Citracal (Mission Pharmacal Australia Pty Ltd, Sydney, NSW, Australia) (HC). The solid components of all meals were of a similar weight (about $400 \mathrm{~g}$ ) and fluids consumed were of identical volumes $(200 \mathrm{ml})$. The macronutrient content of the breakfast meals was determined using Foodworks analysis package 3.0 (Xyris Software, Highgate Hill, Qld, Australia). All subjects completed a palatability questionnaire that enquired about amount, taste, and overall acceptability of each meal. Each answer was scored on a $15 \mathrm{~cm}$ visual analogue scale anchored by the most negative to the most positive response for each question.

\section{Anthropometry and body composition measurements}

Standing height was measured using a stadiometer fixed to the wall and recorded to the nearest $0.1 \mathrm{~cm}$. Body weight was measured after an overnight fast on each occasion, immediately after voiding, with subjects wearing underwear and a light surgical gown, on a digital balance and recorded to the nearest $100 \mathrm{~g}$. Waist and hip circumferences were measured as described by Norton \& Olds (2000). Body composition was determined by dual-energy X-ray absorptiometry (Lunar DPX-L, Madison, WI, USA) at a certified commercial bone densitometry centre.

\section{Measurement protocol}

Subjects were requested to abstain from any strenuous exercise for $36 \mathrm{~h}$ before the measurement. All subjects were provided with 2 litres de-ionised water for ad libitum consumption $12 \mathrm{~h}$ before the study. They were provided with 
Table 2. Nutrient composition of the test meals

(Mean values with their standard errors)

\begin{tabular}{|c|c|c|c|c|c|c|}
\hline \multirow[b]{2}{*}{ Diet... } & \multicolumn{2}{|c|}{ LD } & \multicolumn{2}{|c|}{$\mathrm{HC}$} & \multicolumn{2}{|c|}{$H D$} \\
\hline & Mean & SEM & Mean & SEM & Mean & SEM \\
\hline Energy content (kJ) & $2391 \cdot 0$ & 0.028 & $2386 \cdot 9$ & 0.29 & $2372 \cdot 8$ & 0.46 \\
\hline Protein $(\mathrm{g})$ & 20.7 & 0.004 & $20 \cdot 7$ & 0.002 & $21 \cdot 1$ & 0.004 \\
\hline Protein (\% total energy) & $14 \cdot 7$ & 0.002 & $14 \cdot 7$ & 0.001 & $15 \cdot 1$ & 0.001 \\
\hline Total fat $(\mathrm{g})$ & $22 \cdot 0$ & 0.003 & $21 \cdot 6$ & 0.009 & $22 \cdot 1$ & 0.001 \\
\hline Total fat (\% total energy) & 34 & 0.004 & 33.4 & 0.013 & 34.5 & 0.005 \\
\hline Carbohydrate $(\mathrm{g})$ & 69.9 & 0.00 & $70 \cdot 7$ & 0.016 & $68 \cdot 3$ & 0.03 \\
\hline Carbohydrate (\% total energy) & $46 \cdot 8$ & 0.005 & $47 \cdot 4$ & 0.006 & $46 \cdot 0$ & 0.01 \\
\hline Fibre $(g)$ & 4.9 & 0.001 & 4.9 & 0.002 & 4.7 & 0.005 \\
\hline $\mathrm{Ca}(\mathrm{mg})$ & $175 \cdot 8$ & 0.04 & 575 & 0.001 & $531 \cdot 7$ & 0.05 \\
\hline Vitamin D $(\mathrm{nmol} / \mathrm{l})^{*}$ & 40 & & 45 & & 364 & \\
\hline Volume $(\mathrm{ml})^{\dagger}$ & 365 & & 350 & & 362 & \\
\hline Weight $(g)$ & $401 \cdot 1$ & 0.05 & $408 \cdot 1$ & 0.032 & $408 \cdot 7$ & 0.04 \\
\hline
\end{tabular}

LD, low dairy $\mathrm{Ca}$ and vitamin $\mathrm{D}$ (control); HC, high non-dairy $\mathrm{Ca}$ (calcium citrate) and low vitamin D; HD, high dairy Ca and vitamin D.

* Vitamin D content was calculated using US data for one sample of each of the three test meals (Institute of Medicine Food and Nutrition Board, 1999).

†Volume was calculated by the analysis of one meal as a sample of each of the three test meals.

the same low-fat meal containing $<50 \mathrm{mg} \mathrm{Ca}$, which was consumed on the night before each trial day. Subjects arrived at the laboratory after a $12 \mathrm{~h}$ overnight fast, and emptied their bladder (the time was recorded); the subjects were then weighed. They lay supine for a mandatory $30 \mathrm{~min}$ rest period, while the Deltatrac II metabolic monitor (Datex Ohmeda, Helsinki, Finland) was calibrated. At the end of this rest period, the canopy was placed over the head of the subject and they were asked to remain awake and motionless, as far as possible, for a $30 \mathrm{~min}$ RMR measurement. This protocol yields an RMR not very different from a BMR measurement obtained immediately on awaking, after an overnight stay in the laboratory (Soares et al. 1989).

After the RMR measurement, the plastic canopy was removed and a fasting blood sample $(15 \mathrm{ml})$ was collected. Following the blood collection subjects made a fasting collection of urine. They were given a breakfast meal (Table 2), which they consumed within $10 \mathrm{~min}$. The palatability questionnaire was completed at this time. After $20 \mathrm{~min}$ into each postprandial hour, subjects returned to the supine position and rested for $10 \mathrm{~min}$. The canopy was then placed over their head and measurements made for the last $30 \mathrm{~min}$ of the hour. The first 5 min was not included in subsequent data analysis. In between measurements subjects were allowed to sit up in bed and listen to music, or read. Some elected to sit at a table close to the bed, where they did craft work or read a book. An intermittent measurement protocol provides accurate postprandial data relative to that obtained by continuous minute-to-minute measurement over the postprandial period (Piers et al. 1992). De-ionised water was allowed ad libitum over the first postprandial visit, and the amount consumed was noted. These amounts were kept constant for subsequent visits. All subjects made two separate urine collections, one between 0 and $3 \mathrm{~h}$ and another $3-6 \mathrm{~h}$ after the meal. The weight and duration of all collections were noted, urines were acidified and a sample was frozen at $-80^{\circ} \mathrm{C}$. Total urinary $\mathrm{N}$ excretion was estimated by the Kjeldahl technique. All subjects were offered a buffet meal before they returned home.

\section{Resting metabolic rate}

RMR was measured by indirect calorimetry using a Deltatrac II metabolic monitor (Datex Ohmeda), an open-circuit ventilated canopy measurement system. The measurement was conducted under standardised conditions, as in our previous studies (Piers et al. 2002) with subjects lying (a) at complete physical rest; (b) in a thermally neutral environment; (c) 12 $14 \mathrm{~h}$ after their last meal and a minimum of $8 \mathrm{~h}$ sleep; (d) awake and emotionally undisturbed; (e) without disease and fever. The within-subject CV in RMR was $3.3 \%$ in the present study. The Deltatrac II was calibrated on the morning of each experimental day. Performance of the instrument was also checked at regular intervals during the study period by monitoring the $\mathrm{CO}_{2}$ produced: $\mathrm{O}_{2}$ consumed ratio, during a $30 \mathrm{~min}$ ethanol burn. The mean ratio for twenty ethanol burns was 0.663 (SD 0.008), with a CV of $1.2 \%$.

\section{Diet-induced thermogenesis and substrate oxidation rates}

Diet-induced thermogenesis was measured as described previously (Piers et al. 1992), and expressed in absolute values $(\mathrm{kJ} / 6 \mathrm{~h})$ and as a percentage of the energy in the breakfast meal. Whole-body substrate oxidation rates were calculated at rest (fasting), and for every hour up to $6 \mathrm{~h}$ postprandial, using measures of $\mathrm{O}_{2}$ consumption, $\mathrm{CO}_{2}$ production and urinary $\mathrm{N}$ excretion in that postprandial phase. The equations of Ferranini (1988) were used to calculate energy expenditure and substrate oxidation rates.

\section{Blood assays}

Venous blood samples were drawn at baseline and at the end of each 30 min RMR measurement. Blood for determination of insulin, total cholesterol, LDL-cholesterol (by calculation), HDL-cholesterol and triacylglycerol, NEFA and glycerol was left to stand for $30 \mathrm{~min}$ at room temperature and then centrifuged at $3000 \mathrm{~g}$ for $10 \mathrm{~min}$. Serum was extracted and the samples stored 
at $-80^{\circ} \mathrm{C}$ until later analysis. A finger prick blood sample was also taken and blood glucose was measured using Accu-Chek Active glucose strips (Roche Diagnostic, Castle Hill, NSW, Australia). Serum insulin was measured by ELISA based on two monoclonal antibodies (Dako Diagnostic, Ely, Cambs, UK) according to the manufacturer's instructions. Serum triacylglycerol and total cholesterol were measured by enzymic colorimetric kits (TRACE Scientific Ltd, Melbourne, Vic, Australia). Serum HDL-cholesterol was determined after prior precipitation of apo B-containing lipoproteins with phosphotungstic acid and $\mathrm{MgCl}_{2}$ by enzymic colorimetry (TRACE Scientific Ltd). Serum LDL-cholesterol was determined by using a modified version of the Friedewald equation: LDLcholesterol $=(($ total cholesterol $)-($ HDL-cholesterol $)-$ $(0.46 \times$ (triacylglycerol)) (Bairaktari et al. 2000). NEFA and glycerol were determined by an enzymic colorimetric method (WAKO NEFA-C Kit; Novachem pty Ltd, Collingwood, Vic, Australia and Randox Ltd, Crumlin, Co. Antrim, UK). Individual $\mathrm{CV}_{\text {intra }} \%$ were $<2.1 \%$ (glucose), $\mathrm{CV}_{\text {intra }} \%$ and $\mathrm{CV}_{\text {inter }} \%$ $<5 \%$ (insulin), $<2 \%$ (total cholesterol), $<2 \%$ (HDL), $<2 \%$ (triacylglycerol) and $<5 \%$ for both NEFA and glycerol.

\section{Statistical analysis}

All data are presented as means with their standard errors, unless otherwise stated. Change between fasting and fed states was calculated by subtracting the fasting value $X$ duration of measurement from the total postprandial value over $6 \mathrm{~h}$. Since the intervals of measurement in the postprandial period were equal, this summary statistic was analogous to determining the incremental area under the curve (Mathews et al. 1990). Total postprandial fat and carbohydrate oxidation were also adjusted for their respective fasting values using the method of Ravussin \& Bogardus (1989). A repeated-measures ANOVA was used to determine statistical significance, which was set at the $5 \%$ level. Post hoc testing used the least significant difference procedure. Pearson's correlation coefficients for all anthropometric, body composition and metabolic variables were separately calculated for each meal. Data were analysed using the SPSS for Windows statistical software package (version 11; SPSS Inc., Chicago, IL, USA).

\section{Results}

The physical characteristics of the subjects are shown in Table 1 . Sensory evaluation of the test meals showed no significant difference in the scores for 'amount' (LD 9.3 (SEM 3.2) cm; HC 7.3 (SEM 3.0) cm; HD 6.7 (SEM $2.6 \mathrm{~cm}$ ), 'taste' (LD 12.8 (SEM 2.5) cm; HC 12.7 (SEM 2.4) cm; HD $11.8($ SEM 3.3) $\mathrm{cm}$ ) and 'overall acceptability' of each meal (LD 12.9 (SEM 2.5) cm; HC 14.1 (SEM 0.7) cm; HD 13.5 (SEM 1.2) cm).

\section{Effect of breakfast meals}

Energy expenditure and substrate oxidation. There was no significant difference in body weight or RMR between the three trials. However, basal fat oxidation rate (FOR) was significantly higher following the low-Ca meal, and carbohydrate oxidation rate (COR) significantly lower, despite randomisation of the test meals (Table 3). Diet-induced thermogenesis, in absolute terms $(\mathrm{kJ} / 6 \mathrm{~h})$ or as percentage of energy in meal $(\%)$, was not different between test meals (Table 3). There was a significant rise in RQ following all meals, but the change in RQ was significantly $(P=0.029)$ lower by 12.7 and $7.8 \%$ following the $\mathrm{HC}$ and $\mathrm{HD}$ meals, respectively (Table 4). Fat oxidation was significantly suppressed after each meal, but the suppression was significantly less by 38 and $44 \%$ following the $\mathrm{HC}$ and $\mathrm{HD}$ meals, respectively (Table 4). Reciprocally, the increase in carbohydrate oxidation ( $\triangle \mathrm{COR})$ was significantly $(P=0.027)$ lower by $60 \%(\mathrm{HC})$ and $55.4 \%$ (HD) compared with the LD meal (Table 4). Sum of postprandial FOR adjusted for fasting values was also significantly different between meals $(P=0 \cdot 039)$, with the rank order meal $\mathrm{LD}<$ meal HC $<$ meal HD (Table 4 ). The sum of postprandial COR adjusted for fasting values showed a trend to be lowest following the HD meal $(P=0.06$; Table 4$)$.

Substrates and hormones. There were no significant differences between the three meals for basal or postprandial glucose or insulin concentrations (Table 4; Fig. 1 (A and B)). Following all meals, postprandial NEFA levels were suppressed, with the HD meal significantly less suppressed over the $6 \mathrm{~h}$ postprandial period relative to the LD meal (LD - 1.50 (SEM 0.26) $\mathrm{mmol} / \mathrm{l}$; $\mathrm{HC}-1.22$ (SEM 0.32) mmol/l; HD - 0.94 (SEM 0.27) $\mathrm{mmol} / \mathrm{l}$; $P=0 \cdot 035$ ) (Fig. 2 (A)). Serum glycerol was less suppressed

Table 3. Fasting measurements before the three test meals

(Mean values with their standard errors for eight subjects)

\begin{tabular}{|c|c|c|c|c|c|c|c|}
\hline \multirow[b]{2}{*}{ Meal... } & \multicolumn{2}{|c|}{ LD } & \multicolumn{2}{|c|}{$\mathrm{HC}$} & \multicolumn{2}{|c|}{$\mathrm{HD}$} & \multirow{2}{*}{$\begin{array}{l}\text { Significance by ANOVA for } \\
\text { repeated measures }(P)\end{array}$} \\
\hline & Mean & SEM & Mean & SEM & Mean & SEM & \\
\hline $\mathrm{RQ}$ & $0 \cdot 80^{\mathrm{a}}$ & 0.02 & $0.89^{b}$ & 0.02 & $0.85^{b}$ & 0.02 & 0.009 \\
\hline Protein oxidation (g/h) & $3 \cdot 0$ & 0.4 & $3 \cdot 33$ & 0.2 & 3.8 & 0.7 & 0.26 \\
\hline Fat oxidation $(\mathrm{g} / \mathrm{h})$ & $4 \cdot 1^{\mathrm{a}}$ & 0.5 & $1.9^{b}$ & 0.7 & $2 \cdot 9^{a b}$ & 0.6 & 0.003 \\
\hline Carbohydrate oxidation $(\mathrm{g} / \mathrm{h})$ & $5 \cdot 3^{a}$ & $1 \cdot 2$ & $10 \cdot 2^{b}$ & 1.6 & $7 \cdot 4^{\mathrm{ab}}$ & $1 \cdot 1$ & 0.026 \\
\hline Serum insulin $(\mu \mathrm{IU} / \mathrm{ml})$ & 11.83 & $4 \cdot 20$ & $13 \cdot 11$ & 4.84 & $10 \cdot 63$ & 4.29 & 0.31 \\
\hline Serum NEFA (mmol/l) & 0.65 & 0.076 & 0.627 & 0.076 & 0.615 & 0.092 & 0.54 \\
\hline Serum glycerol $(\mu \mathrm{mol} / \mathrm{l})$ & $77 \cdot 86$ & 5.45 & $73 \cdot 73$ & 5.84 & $76 \cdot 39$ & 7.99 & 0.27 \\
\hline
\end{tabular}

LD, low dairy $\mathrm{Ca}$ and vitamin $\mathrm{D}$ (control); $\mathrm{HC}$, high non-dairy $\mathrm{Ca}$ (calcium citrate) and low vitamin $\mathrm{D}$; HD, high dairy Ca and vitamin $\mathrm{D}$.

a,b Mean values within a row with unlike superscript letters were significantly different $(P<0.05$; post hoc least significant difference procedure). 
Table 4. The influence of the source of calcium on postprandial thermogenesis and substrate oxidation (Mean values with their standard errors for eight subjects)

\begin{tabular}{|c|c|c|c|c|c|c|c|}
\hline & \multicolumn{2}{|c|}{ LD } & \multicolumn{2}{|c|}{$\mathrm{HC}$} & \multicolumn{2}{|c|}{$\mathrm{HD}$} & \multirow{2}{*}{$\begin{array}{l}\text { Significance by ANOVA for } \\
\text { repeated measures }(P)\end{array}$} \\
\hline & Mean & SEM & Mean & SEM & Mean & SEM & \\
\hline DIT (\%) & $6 \cdot 5$ & $1 \cdot 1$ & $7 \cdot 2$ & 1.4 & $7 \cdot 0$ & 0.8 & 0.58 \\
\hline Change in $R^{*}$ & $0.32^{a}$ & 0.09 & $-0.039^{b}$ & 0.08 & $-0.024^{b}$ & $0 \cdot 11$ & 0.029 \\
\hline Change in protein oxidation $(\mathrm{g} / 6 \mathrm{~h})^{*}$ & $-11 \cdot 5$ & $2 \cdot 4$ & $-13 \cdot 7$ & 0.7 & $-16 \cdot 7$ & $4 \cdot 4$ & 0.31 \\
\hline $\begin{array}{l}\text { Change in carbohydrate } \\
\text { oxidation }(\mathrm{g} / 6 \mathrm{~h}) *\end{array}$ & $34 \cdot 1^{a}$ & $7 \cdot 6$ & $13 \cdot 6^{b}$ & $7 \cdot 5$ & $15 \cdot 2^{b}$ & $7 \cdot 1$ & 0.032 \\
\hline $\begin{array}{l}\text { Adjusted sum of carbohydrate } \\
\text { oxidation }(\mathrm{g} / 6 \mathrm{~h}) \dagger\end{array}$ & $68 \cdot 0$ & $5 \cdot 1$ & $72 \cdot 5$ & $4 \cdot 8$ & $59 \cdot 8$ & $7 \cdot 5$ & 0.061 \\
\hline Change in fat oxidation $(\mathrm{g} / 6 \mathrm{~h})^{*}$ & $-6 \cdot 5^{\mathrm{a}}$ & $2 \cdot 2$ & $2 \cdot 9^{\mathrm{b}}$ & $2 \cdot 3$ & $3 \cdot 3^{b}$ & 2.5 & 0.005 \\
\hline Adjusted sum of fat oxidation $(\mathrm{g} / 6 \mathrm{~h}) \dagger$ & $14 \cdot 1^{\mathrm{a}}$ & $1 \cdot 8$ & $18 \cdot 2^{\mathrm{ab}}$ & 1.7 & $20 \cdot 9^{b}$ & $2 \cdot 4$ & 0.039 \\
\hline Change in glucose $(\mathrm{mmol} / \mathrm{l})$ & $2 \cdot 04$ & $1 \cdot 25$ & 1.65 & 0.50 & $1 \cdot 73$ & 1.02 & 0.76 \\
\hline Change in insulin $(\mu \mathrm{IU} / \mathrm{ml})^{\star}$ & 181.93 & $50 \cdot 18$ & $188 \cdot 18$ & 31.90 & 193.09 & $40 \cdot 16$ & 0.73 \\
\hline Change in NEFA (mmol/l)* & $-1 \cdot 50^{\mathrm{a}}$ & 0.26 & $-1 \cdot 22^{\mathrm{ab}}$ & 0.32 & $-0.94^{b}$ & 0.27 & 0.035 \\
\hline Change in glycerol $(\mu \mathrm{mol} / \mathrm{l})^{*}$ & $-48 \cdot 29$ & $27 \cdot 0$ & 0.99 & $25 \cdot 62$ & $2 \cdot 31$ & $26 \cdot 78$ & 0.31 \\
\hline
\end{tabular}

LD, low dairy $\mathrm{Ca}$ and vitamin $\mathrm{D}$ (control); HC, high non-dairy $\mathrm{Ca}$ (calcium citrate) and low vitamin D; HD, high dairy Ca and vitamin D. DIT, diet-induced thermogenesis.

a,b Mean values within a row with unlike superscript letters were significantly different $(P<0.05$; post hoc least significant difference procedure).

${ }^{*}$ Calculated as sum of postprandial values over $6 \mathrm{~h}-$ (fasting value per $\mathrm{h} \times 6$ ).

† Calculated as sum of postprandial values over $6 \mathrm{~h}$ adjusted for fasting baseline.

after the HD meal by almost $70 \%$ but results did not attain statistical significance (LD - 48.30 (SEM 27.0) $\mu \mathrm{mol} / \mathrm{l}$; HC 1.0 (SEM 25.62) $\mu \mathrm{mol} / \mathrm{l}$; HD 2.3 (SEM 26.78) $\mu \mathrm{mol} / \mathrm{l} ; P=0 \cdot 31$ ) (Fig. 2 (B)). Pearson's correlations did not detect any significant relationships between variables.

\section{Discussion}

The regulation of fat balance is critical to energy balance and the equilibrium of fat stores in the body (Flatt, 1995). Fat balance is determined by the body's ability to match fat oxidation to fat intake. Any dietary factor that can stimulate fat oxidation over a prolonged period would hence reduce fat stores, provided there was no compensatory increase in fat intake. We pursued the idea that $\mathrm{Ca}$ and other ingredients in dairy products may help alter body composition if they could either stimulate whole-body fat oxidation, increase postprandial energy expenditure or accelerate mobilisation of fat stores (lipolysis).
For this purpose the control test meal was low in dairy (and Ca) and vitamin D (LD). The second experimental meal (HC) was a high-Ca meal using calcium citrate (pharmacological). There is evidence to indicate that $\mathrm{Ca}$ is better absorbed as calcium citrate in both fasting and mixed-meal situations (Sakhaee et al. 1999). In addition, this meal was served with orange juice to maximise the absorption of the calcium citrate tablets (Mehansho et al. 1989; Heaney et al. 2005). The third meal (HD) was high in dairy and hence $\mathrm{Ca}$ with additional vitamin D (see p. 2). Vitamin D was added to enhance the absorption of Ca (Holick, 2004) and to mimic the US practice of fortifying all dairy products with vitamin D (Newmark et al. 2004).

There were no differences in the taste preference and overall acceptability of each meal. Palatability of a test meal is known to affect insulin responses and ultimately substrate utilisation (Sawaya et al. 2001). The amount and volume of each meal were also similar (Table 2) and led to similar gastric emptying, based on the paracetamol absorption test
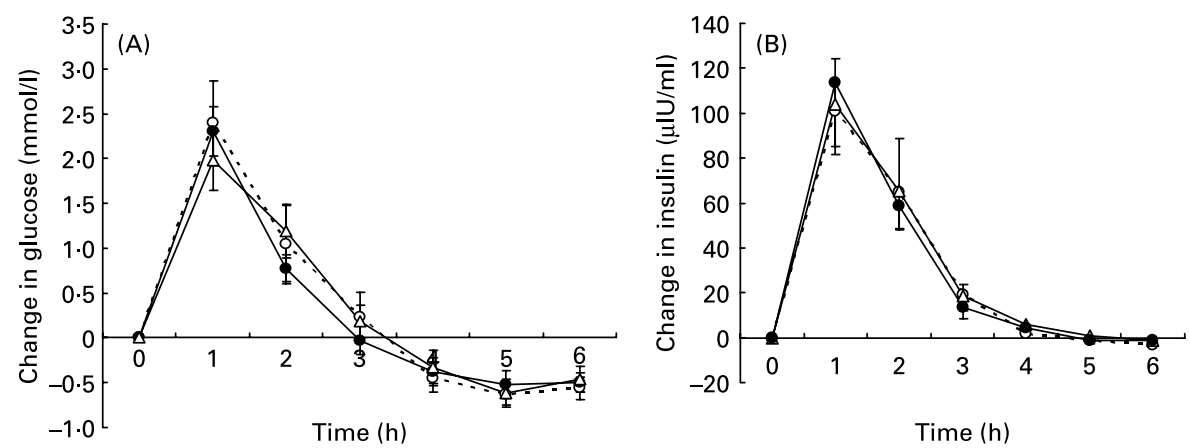

Fig. 1. (A) Changes from fasting values for glucose responses in eight subjects, following breakfast meals low in dairy and Ca (O), no dairy but high in Ca ( $\bullet$ ) and high in dairy and $\mathrm{Ca}(\Delta)$. Values are means, with their standard errors represented by vertical bars. Repeated-measures ANOVA shows a significant effect of time $(P=0.014)$, no significant effect of meal $(P=0.886)$ and no meal $\times$ time interaction $(P=0.293)$. (B) Changes from fasting values for insulin responses in eight subjects, following breakfast meals low in dairy and $\mathrm{Ca}(O)$, no dairy but high in $\mathrm{Ca}(\bullet)$ and high in dairy and $\mathrm{Ca}(\Delta)$. Values are means, with their standard errors represented by vertical bars. Repeated-measures ANOVA shows a significant effect of time $(P=0.003)$, no significant effect of meal $(P=0.729)$ and no meal $\times$ time interaction $(P=0.604)$. 

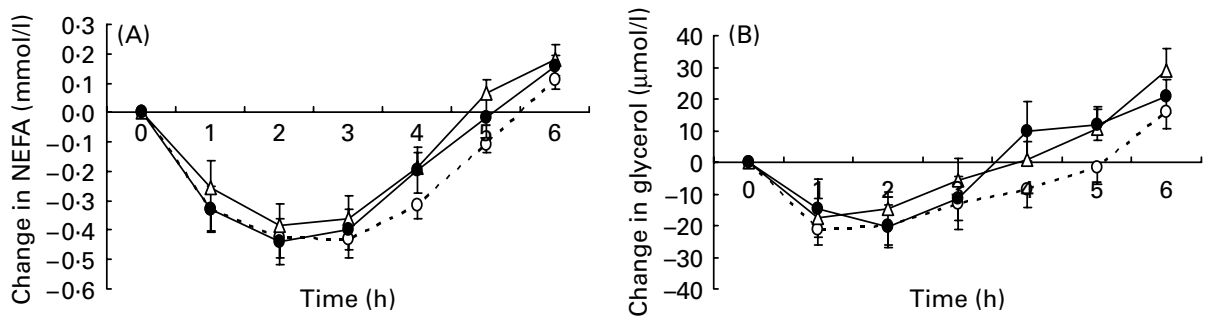

Fig. 2. (A) Changes from fasting values for NEFA responses in eight subjects, following breakfast meals low in dairy and Ca $(O)$, no dairy but high in Ca $(\bullet)$ and high in dairy and $\mathrm{Ca}(\Delta)$. Values are means, with their standard errors represented by vertical bars. Repeated-measures ANOVA shows a significant effect of time $(P=0.005)$, a significant effect of meal $(P=0.035)$ and no meal $\times$ time interaction $(P=0.593)$. (B) Changes from fasting values for glycerol responses in eight subjects, following breakfast meals low in dairy and $\mathrm{Ca}(O)$, no dairy but high in $\mathrm{Ca}(\bullet)$ and high in dairy and $\mathrm{Ca}(\Delta)$. Values are means, with their standard errors represented by vertical bars. Repeated-measures ANOVA shows a significant effect of time $(P=0.012)$, no significant effect of meal $(P=0.28)$ and no meal $\times$ time interaction $(P=0.538)$.

(Cummings et al. 2004). Hence, neither palatability nor gastric emptying of the test meals is expected to confound the outcomes.

\section{Fat oxidation following calcium}

We observed that subjects acutely fed a high-dairy or high-Ca meal exhibited a lesser suppression of FOR over a $6 \mathrm{~h}$ postprandial period, when compared with a low dairy $\mathrm{Ca}$ meal. These findings have been confirmed by our group using a sequential meal design (Soares et al. 2004b). The present results also compare favourably with evidence from the literature. In a cross-sectional study, Melanson et al. (2003) showed a positive correlation $(r 0.38 ; P=0.03)$ between acute $\mathrm{Ca}$ intake and fat oxidation using whole-body room calorimetry. Moreover, in a prospective study of energy restriction, these authors showed a greater $24 \mathrm{~h}$ fat oxidation following high Ca intakes (Melanson et al. 2005). One long-term study has also demonstrated a greater FOR in subjects who followed a high-Ca diet for 1 year (Gunther et al. 2005). In contrast, Jacobsen et al. (2005) manipulated Ca and protein intakes over 2-week periods and did not find any change in $24 \mathrm{~h}$ energy expenditure or fat oxidation between diets.

In the present study, circulating levels of NEFA were less suppressed following both high-Ca meals (Fig. 2 (A)), which paralleled the changes in fat oxidation. The similar glycaemic and insulinaemic responses following all three meals (Figs. 1(A and B)) would suggest that the relatively elevated NEFA levels did not result from a reduced insulin action. Frayn (1998) and Coppack et al. (1994) have argued that following a mixed meal, chylomicron triacylglycerol is preferentially acted upon by adipose tissue lipoprotein lipase. While re-esterification into triacylglycerol does occur, much of this NEFA fails to be 'trapped' within adipose tissue and finds itself back in circulation.

A role for the sympathetic nervous system in postprandial events cannot be discounted. Sympathetic nervous system activity contributes to meal-induced thermogenesis, and is a potent stimulator of adipose tissue lipolysis (Coppack et al. 1994). Although not statistically significant, the postprandial changes in serum glycerol were similar between the two high$\mathrm{Ca}$ meals, and about $70 \%$ higher relative to the low-Ca meal (Fig. 2 (B)). Evidence of a significantly higher glycerol level following high $\mathrm{Ca}$ intakes has also been obtained under hypoenergetic conditions (Zemel et al. 2005a,b), as well as during weight maintenance (Zemel et al. 2005b). While we acknowledge that measurements of circulating glycerol are not the best quantitative index of adipose tissue lipolysis, the consistency of effects across studies merits further investigation. We anticipated a higher diet-induced thermogenesis between meals, but could not demonstrate such an effect. Hence higher intakes of $\mathrm{Ca}$ acutely modulate the type of fuel being utilised in the postprandial state, without a change in energy production. The $\mathrm{Ca}$ content of the meals tested in the present study $(530-575 \mathrm{mg})$ would in all probability exceed what is habitually consumed at individuals meals. Whether this would result in an attenuation of the effect on fat oxidation remains a possibility, but requires dose-response studies for confirmation. Second, an increased frequency of $\mathrm{Ca}$ consumption would increase the net amount absorbed for the day. Hence both factors are important when extrapolating results from acute meal-based studies to dietary prescription for body-weight regulation.

In any study involving the manipulation of a nutrient, it is important to be reassured that the results are not biased by poor absorbance of that nutrient. We have examined three markers of $\mathrm{Ca}$ bioavailability; intact parathyroid hormone suppression, serum ionised $\mathrm{Ca}$ and urinary $\mathrm{Ca}$ excretion. The rank order of bioavailability was similar across all methods with meal $\mathrm{LD}<$ meal HD $<$ meal HC (Cummings \& Soares, 2005). The observations that FOR following the HD meal were similar to after the $\mathrm{HC}$ meal, despite poorer bioavailability of $\mathrm{Ca}$, may indicate the presence of other bioactive components in dairy products that influence fat oxidation (Zemel, 2002, 2003; Parikh \& Yanovski, 2003).

To the best of our knowledge, the present prospective study is the first to show a greater postprandial FOR following high$\mathrm{Ca}$ meals, both dairy and non-dairy. The lesser postprandial suppression of NEFA would drive the increase in the fat oxidation, and the trend for a greater lipolysis would serve to maintain the relatively higher NEFA levels following such meals. Such data provide a mechanistic framework for understanding how the intake of Ca-rich foods may lead to a greater fat loss in obese human subjects undergoing energy restriction. Further confirmation of the acute, and chronic benefits of $\mathrm{Ca}$ are required to place these observations on a firmer footing.

\section{Acknowledgements}

N. K. C. was responsible for the subject recruitment, diet compilation, data collection, statistical analysis and writing of the manuscript. A. P. J. assisted with data collection, analysis and interpretation. M. J. S. generated the idea, study design, obtained 
funding, assisted with statistical analysis and the writing of the manuscript. The authors thank the volunteers for their time and cooperation during the present study. We acknowledge the laboratory skills of Pushpa Sivakumar and thank Murray Goulburn Co-operative Company Ltd for provision of the specialised milk. The study was funded by a Dairy Australia grant CUT 10481.

\section{References}

Australian Bureau of Statistics (1998) Nutrient intakes and physical measurements. Canberra: Australian Bureau of Stastistics.

Bairaktari E, Hatzidimou K, Tzallas C, Vini M, Katsaraki A, Tselepis A, Elisaf M \& Tsolas O (2000) Estimation of LDL cholesterol based on the Friedewald formula and on apo B levels. Clin Biochem 33, 549-555.

Coppack SW, Jensen MD \& Miles JM (1994) In vivo regulation of lipolysis in humans. J Lipid Res 35, 177-193.

Cummings NK \& Soares MJ (2005) Calcium bioavailability from dairy and non-dairy sources: possible suppression effect of paracetamol (Acetaminophen). Asia Pac J Clin Nutr 14, Suppl., S103.

Cummings NK, Soares MJ, Chan She Ping-Delfos W, James AP, Sivakumar P, Mamo J \& Piers LS (2004) Gastric emptying of high calcium breakfast meals: potential effect of paracetamol (acetaminophen) on substrate oxidation rates. Aust Soc Study Obes 79, P25.

Davies MK, Heaney RP \& Recker RP (2000) Calcium intake and body weight. J Clin Endocrinol Metab 85, 4635-4638.

Ferranini E (1988) The theoretical bases of indirect calorimetry: a review. Metabolism 37, 287-301.

Flatt JP (1995) Body composition, respiratory quotient and weight maintenance. Am J Clin Nutr 62, 1107S-1117S.

Frayn KN (1998) Non-esterified fatty acid metabolism and postprandial lipaemia. Atherosclerosis 141, S41-S46.

Gunther CW, Lyle RM, Legowski PA, James JM, McCabe LD, McCabe GP, Peacock M \& Teegarden D (2005) Fat oxidation and its relation to serum parathyroid hormone in young women enrolled in a 1-y dairy calcium intervention. Am J Clin Nutr 82, 1228-1234.

Harvey-Berino J, Gold BC, Lauber R \& Starinski A (2005) The impact of calcium and dairy product consumption on weight loss. Obes Res 13, 1720-1726.

Heaney RP, Rafferty K, Dowell MS \& Bierman J (2005) Calcium fortification systems differ in bioavailability. J Am Diet Assoc 105, 807-809.

Holick MF (2004) Vitamin D: importance in the prevention of cancers, type 1 diabetes, heart disease, and osteoporosis. Am J Clin Nutr 79, 362-371.

Institute of Medicine Food and Nutrition Board (1999) Dietary Reference Intakes: calcium, phosphorus, magnesium, vitamin D and fluoride. Washington DC: National Academy Press.

Jacobsen R, Lorenzen JK, Toubro S, Krog-Mikkelsen I \& Astrup A (2005) Effect of short-term high dietary calcium intake on 24-h energy expenditure, fat oxidation, and fecal fat excretion. Int $J$ Obes (Lond) 29, 292-301.

Mathews JN, Altman DG, Campbell MJ \& Royston P (1990) Analysis of serial measurements in medical research. BMJ 300, 230-235.

Mehansho H, Kanerva RL, Hudepohl GR \& Smith KT (1989) Calcium bioavailability and iron-calcium interaction in orange juice. $J$ Am Coll Nutr 8, 61-68.

Melanson EL, Donahoo WT, Dong F, Ida T \& Zemel MB (2005) Effect of low- and high-calcium dairy-based diets on macronutrient oxidation in humans. Obes Res 13, 2102-2112.
Melanson EL, Sharp TA, Schneider J, Donahoo WT, Grunwald GK \& Hill JO (2003) Relation between calcium intake and fat oxidation in adult humans. Int J Obes Relat Metab Disord 27, 196-203.

National Health and Medical Research Council (1997) Acting on Australia's Weight: A Strategic Plan for the Prevention of Overweight and Obesity. Canberra: Australian Government Publishing Service.

Newmark HL, Heaney RP \& Lachance PA (2004) Should calcium and vitamin $\mathrm{D}$ be added to the current enrichment program for cereal-grain products? Am J Clin Nutr 80, 264-270.

Norton K \& Olds T (2000) Anthropometrica. Sydney: University of New South Wales Press.

Nowson CA \& Margerison C (2002) Vitamin D intake and vitamin D status of Australians. Med J Aust 177, 149-152.

Parikh SJ \& Yanovski JA (2003) Calcium intake and adiposity. Am J Clin Nutr 77, 1-7.

Piers LS, Soares MJ, Makan T \& Shetty PS (1992) Thermic effect of a meal 1 . Methodology and variation in normal young adults. $\mathrm{Br} J$ Nutr 67, 165-175.

Piers LS, Walker KZ, Stoney RM, Soares MJ \& O’Dea K (2002) The influence of the type of dietary fat on postprandial fat oxidation rates: monounsaturated (olive oil) vs. saturated fat (cream). Int $J$ Obes Relat Metab Disord 26, 814-821.

Ravussin E \& Bogardus C (1989) Relationship of genetics, age, and physical fitness to daily energy expenditure and fuel utilization. Am J Clin Nutr 49, 968-975.

Sakhaee K, Bhuket T, Adams-Huet B \& Rao DS (1999) Meta-analysis of calcium bioavailability: a comparison of calcium citrate with calcium carbonate. Am J Ther 6, 313-321.

Sawaya AL, Fuss PJ, Dallal GE, Tsay R, McCrory MA, Young V \& Roberts SB (2001) Meal palatability, substrate oxidation and blood glucose in young and older men. Physiol Behav 72, 5-12.

Soares MJ, Binns C \& Lester L (2004a) Higher intakes of calcium are associated with lower BMI and waist circumference in Australian adults: an examination of the 1995 National Nutrition Survey. Asia Pac J Clin Nutr 13, S85.

Soares MJ, Piers LS, Kraai L \& Shetty PS (1989) Day-to-day variations in basal metabolic rates and energy intakes of human subjects. Eur J Clin Nutr 43, 465-472.

Soares MJ, Ping-Delfos WC, James AP \& Cummings NK (2004b) Dairy calcium and vitamin D stimulate postprandial thermogenesis: effect of sequential meals. Asia Pac J Clin Nutr 13, S56.

Thompson WG, Rostad Holdman N, Janzow DJ, Slezak JM, Morris KL \& Zemel MB (2005) Effect of energy-reduced diets high in dairy products and fiber on weight loss in obese adults. Obes Res 13, $1344-1353$.

Thorburn AW (2005) Prevalence of obesity in Australia. Obes Rev 6 , 187-189.

Zemel MB (2002) Regulation of adiposity and obesity risk by dietary calcium: mechanisms and implications. J Am Coll Nutr 21, 146S-151S.

Zemel MB (2003) Mechanisms of dairy modulation of adiposity. J Nutr 133, 252S-256S.

Zemel MB (2004) Role of calcium and dairy products in energy partitioning and weight management. Am J Clin Nutr 79, Suppl., 907S-912S.

Zemel MB, Richards J, Mathis S, Milstead A, Gebhardt L \& Silva E (2005a) Dairy augmentation of total and central fat loss in obese subjects. Int J Obes (Lond) 29, 391-397.

Zemel MB, Richards J, Milstead A \& Campbell P (2005b) Effects of calcium and dairy on body composition and weight loss in AfricanAmerican adults. Obes Res 13, 1218-1225.

Zemel MB, Shi H, Greer B, Dirienzo D \& Zemel P (2000) Regulation of adiposity by dietary calcium. FASEB $J \mathbf{1 4}, 1132-1138$. 